\title{
Diacronie
}

Studi di Storia Contemporanea

$N^{\circ} 22,2$ | 2015

Costruire

\section{Liliana Corobca, Controlul cărŢii. Censura literaturii în regimul comunist din România}

Controlul cărţii. La censura letteraria nel regime comunista in Romania

\section{Francesco Zavatti}

\section{(2) OpenEdition}

\section{Journals}

\section{Edizione digitale}

URL: http://journals.openedition.org/diacronie/2298

DOI: 10.4000/diacronie.2298

ISSN: 2038-0925

\section{Editore}

Association culturelle Diacronie

\section{Notizia bibliografica digitale}

Francesco Zavatti, « Liliana Corobca, Controlul cărtii. Censura literaturii în regimul comunist din România », Diacronie [Online], № 22, 2 | 2015, online dal 01 juin 2015, consultato il 09 octobre 2020. URL : http:// journals.openedition.org/diacronie/2298; DOI : https://doi.org/10.4000/diacronie.2298

Questo documento è stato generato automaticamente il 9 octobre 2020.

Creative Commons License 


\section{Liliana Corobca, Controlul cărŢii.} Censura literaturii în regimul comunist din România

Controlul cărŢii. La censura letteraria nel regime comunista in Romania

\section{Francesco Zavatti}

NOTIZIA

Liliana Corobca, Controlul cărţii. Censura literaturii în regimul comunist din România [Controlul cărŢii. La censura letteraria nel regime comunista in Romania], Bucarest, Cartea Româneasca, 2014, 374 pp. 
Controlul CărŢii era in epoca comunista una sezione della Direzione Generale della Stampa. L'autrice offre tanto un'analisi del funzionamento delle istituzioni adibite alla censura, proponendo un capitolo sui criteri censori, quanto un'analisi dei meccanismi che hanno consentito al regime comunista di creare una generalizzazione della censura all'interno di ogni singola istituzione culturale, e quindi di perpetrare la censura, anche

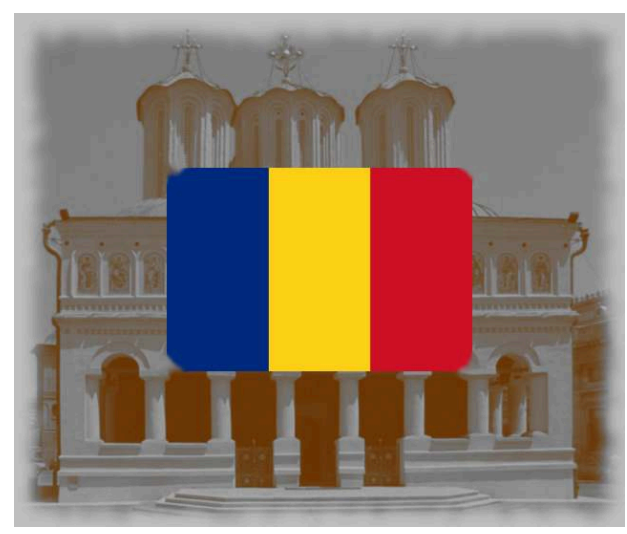
dopo la dismissione della Direzione Generale della Stampa nel 1977. Corobca propone anche un capitolo sulle gerarchie della censura, da quella interiorizzata dagli intellettuali, alla difficile impresa degli autori di non vedere censurati i propri testi, alla censura repressiva, e al grado massimo di censura, cioè la conduzione/manipolazione totalitaria della cultura da parte del partito. Il volume rappresenta un importante punto di passaggio per la storiografia romena sull'epoca comunista, essendo per la prima volta passata in rassegna la storia della Direzione Generale della Stampa, un'istituzione che ha avuto un ruolo essenziale nella produzione di mezzo secolo di cultura nazionale, e della censura come paradigma interpretativo altrettanto centrale nel funzionamento generale del sistema comunista.

\section{AUTORI}

\section{FRANCESCO ZAVATTI}

Classe (1982), è dottorando in Storia presso il Centre for Baltic and East European Studies della Södertörn University, Svezia. Si è laureato in storia (magna cum laude) presso l'Università degli Studi di Modena e Reggio Emilia con una tesi dal titolo Storiografia e Nazionalismo nella Romania di Ceauşescu. Nel periodo 2008-2011, ha collaborato a progetti educativi ed editoriali con l'Istituto della Resistenza e della Storia Contemporanea di Modena. È stato insignito nel 2010 di una borsa di studio da parte della Fondazione Cassa di Risparmio di Modena per condurre un progetto di carattere storico sull'Associazione Nazionale fra Mutilati e Invalidi di Guerra, culminati con la pubblicazione di una monografia Mutilati ed invalidi di guerra: una storia politica. Il caso modenese (Milano, Unicopli, 2011) e una mostra itinerante. Nel 2012, ha ricevuto una borsa di studio dalla Helge Axelsson Johnsons Stiftelsen (Svezia) per condurre ricerche archivistiche nell'Europa dell'Est, nell'ambito del suo dottorato. URL: http://www.studistorici.com/2014/01/06/francesco-zavatti/ 